\title{
Quantitative whole-body MR imaging for assessment of tumor burden in patients with multiple myeloma: correlation with prognostic biomarkers
}

\author{
Mengtian Sun ${ }^{1}$, Jingliang Cheng ${ }^{1}$, Cuiping $\operatorname{Ren}^{1}$, Yong Zhang ${ }^{1}$, Yinhua $\mathrm{Li}^{1}$, Ying $\mathrm{Li}^{1}$, Suping Zhang \\ ${ }^{1}$ Department of Magnetic Resonance, the First Affiliated Hospital of Zhengzhou University, Zhengzhou, China; ${ }^{2}$ Department of Hematology, the \\ First Affiliated Hospital of Zhengzhou University, Zhengzhou, China
}

Correspondence to: Mengtian Sun, MD. Department of Magnetic Resonance, the First Affiliated Hospital of Zhengzhou University, 1st, Jianshe Dong Road, Zhengzhou 450052, China. Email: sunmengtianqing@163.com.

Background: To assess the quantification of tumor burden in multiple myeloma (MM) patients using whole-body magnetic resonance imaging (MRI) and to identify the correlation between MRI parameters and prognostic biomarkers.

Methods: We retrospectively analyzed 95 newly diagnosed MM patients treated at our hospital from June 2018 to March 2020. All patients underwent whole-body MRI examination, including diffusion-weighted whole-body imaging with background body signal suppression (DWIBS), modified Dixon chemical-shift imaging (mDIXON), and short TI inversion recovery (STIR) sequences. The MRI presentation was used to determine MM infiltration patterns and calculate apparent diffusion coefficient (ADC) and a fat fraction (FF). The one-way ANOVA and Kruskal-Wallis test were used to compare the differences of these values between DS, ISS, and R-ISS stages in different MM infiltration patterns. Spearman correlation test was used for correlation analysis of ADC and FF against prognostic biomarkers, and two independent sample $t$-test was used to evaluate the differences of ADC and FF in different free light-chain ratio groups.

Results: The MRI presentation was classified into normal pattern (36 patients; $37.9 \%$ ), diffuse (27 patients; 28.4\%), and focal (32 patients; 33.7\%) infiltration patterns. Statistically significant ADC and FF differences between different DS, ISS, and R-ISS stages were observed in normal/diffuse infiltration patterns but not in focal infiltration patterns. The ADC and FF of the normal/diffuse infiltration pattern showed correlations with hemoglobin, $\beta 2$-microglobulin, bone marrow plasma cells, flow cytometry of bone marrow cells, and serum monoclonal protein. In contrast, $\mathrm{ADC}$ in focal infiltration patterns was negatively correlated with $\beta 2$-microglobulin and C-reactive protein. The FF of patients with a normal/diffuse infiltration pattern was higher in the low free light-chain ratio group than that in the high free light-chain ratio group $(\mathrm{P}=0.023)$.

Conclusions: Our observations indicate that quantitative whole-body functional MRI examination may serve as an effective complement to imaging diagnosis based on morphology and provide further information on the tumor burden of patients with MM.

Keywords: Multiple myeloma (MM); magnetic resonance imaging (MRI); diffusion-weighted whole-body imaging with background body signal suppression (DWIBS); modified Dixon chemical-shift imaging (mDIXON); tumor burden

Submitted Dec 15, 2020. Accepted for publication Apr 01, 2021.

doi: $10.21037 /$ qims-20-1361

View this article at: http://dx.doi.org/10.21037/qims-20-1361

^ ORCID: 0000-0002-6884-247X. 


\section{Introduction}

Multiple myeloma (MM) is a malignancy characterized by the aberrant proliferation of clonal plasma cells in the bone marrow (1). Survival among MM patients has significantly improved due to recent therapeutic advancements and a better understanding of the disease pathogenesis. Since MM shows significant heterogeneity, carrying out sensitive and effective test methods for the precise quantification of newly diagnosed MM patients' tumor burden is clinically important for guiding personalized treatment (2).

Magnetic resonance imaging (MRI) has a high sensitivity for the early detection of marrow infiltration by myeloma cells before bone destruction occurs and can provide a comprehensive assessment of tumor burden in managing patients with plasma cell neoplasms. The first way to assess tumor burden in MRI is by counting the number of focal lesions (FL), which is of prognostic value in asymptomatic $(3,4)$ and symptomatic $(5)$ myeloma. More recently, the use of size (6) or volume (7) of FLs has been introduced to quantify tumor burden from FLs. Secondly, a diffuse MRI marrow pattern has been associated with poor prognosis in MM patients (8-10). Moreover, it has recently been shown that using spinal or spinal plus pelvic MRI may lead to substantial underdiagnoses of smoldering MM patients who actually have $>1 \mathrm{FL}$ in wb MRI (11). The International Myeloma Working Group (IMWG) recommends conducting a whole-body MRI examination for overall evaluation in newly diagnosed MM patients (12). However, objective markers in conventional MRI examinations to determine myelomatous infiltration lesions in MM, especially when this is diffuse, are lacking. There is a need for a combination of sensitive and effective functional imaging to enhance current diagnostic methods for MM (13).

In recent years, functional MRI has undergone continuous development, and diffusion-weighted wholebody imaging with background body signal suppression (DWIBS) can effectively reflect water diffusion in living tissue. The combination of DWIBS and apparent diffusion coefficient (ADC) can effectively evaluate cell density in tumor lesions $(14,15)$. Myeloma cells' infiltration can change the ratio of hematopoietic cells and adipocytes in bone marrow and modified Dixon chemical-shift imaging ( $\mathrm{mDIXON}$ ) can be used to quantify the lipid content in the bone marrow to obtain the fat fraction (FF). This can be used to evaluate the degree of bone marrow infiltration by myeloma cells (16-19). Therefore, we employed functional MRI techniques (DWIBS and mDIXON) and MM biomarkers with prognostic significance as controls and compared $\mathrm{ADC}$ and FF between different stages of MM patients to examine imaging modes that can evaluate $M M$ tumor burden and provide a more informed basis for $M M$ patients.

\section{Methods}

\section{Study subjects}

The ethics committee approved this retrospective study of our hospital, and individual consent for the analysis was waived. We screened newly diagnosed MM patients who were treated at our hospital from June 2018 through March 2020, whose diagnosis was based on the National Comprehensive Cancer Network Guidelines Insights: Multiple Myeloma, Version 3. 2016 (20). Clinical data including gender, age, and prognostic biomarkers such as hemoglobin $(\mathrm{HB})$, serum calcium, serum albumin, serum creatinine, $\beta 2$-microglobulin $(\beta 2-M G)$, serum lactate dehydrogenase (LDH), C-reactive protein (CRP), bone marrow plasma cells (BMPCs), serum monoclonal protein (Serum M-protein), involved/uninvolved serum free lightchain ratio (sFLC-ratio), and flow cytometry of bone marrow cells (FCM) were collected at the first diagnosis (21). Patients were staged according to the Durie-Salmon (DS) staging system (22), International Staging System (ISS) (23), and the Revised International Staging System (R-ISS) (24).

The specific inclusion criteria were (I) clinical diagnosis of MM; (II) DWIBS and mDIXON examinations before treatment; (III) high-quality images without artifacts or distortions; (IV) no bone metabolic disorder due to nonMM causes; (V) no previous anti-bone disease therapy or radiochemotherapy before the examination; (VI) no other active tumors; and (VII) no contraindication to MRI examination.

\section{Scan parameters}

All patients were scanned using a Phillips Ingenia 3.0T MR system (Philips Healthcare, Netherlands) and an integrated whole-body coil. The scan sequences included whole-body DWIBS, whole-body mDIXON, and whole-body STIR sequences, and during the scan, the subjects adopted a supine position, with the head entering the machine first. The DWIBS parameters were as follows: Horizontal axial position scanning, $\mathrm{TR}=9,360 \mathrm{~ms}$, $\mathrm{TE}=63 \mathrm{~ms}$, $\mathrm{TI}=250 \mathrm{~ms}$, FOV $=450 \mathrm{~mm} \times 342 \mathrm{~mm} \times 286 \mathrm{~mm}$, matrix $=192 \times 192$, 
slice thickness $=5 \mathrm{~mm}$, slice gap $=0.2 \mathrm{~mm}$, slices $=55$, scanning segments $=7$ total scan time $=19 \min 40 \mathrm{~s}$, and $\mathrm{b}$ values of 0 and $800 \mathrm{~s} / \mathrm{mm}^{2}$. The mDIXON parameters were as follows: Coronal position scan, based on Fast Field Echo (FFE) sequence, 2-echo 3D acquisition, $\mathrm{TR}=3.6 \mathrm{~ms}$, TE1 $=1.24 \mathrm{~ms}$, TE2 $=2.3 \mathrm{~ms}, \mathrm{FOV}=531 \mathrm{~mm} \times 230 \mathrm{~mm} \times$ $340 \mathrm{~mm}$, matrix $=560 \times 560$, slices $=92$, scanning segments $=6$, total scan time $=1 \mathrm{~min} 45 \mathrm{~s}$, and water-only $(\mathrm{W})$, fat only (F), in phase (IP), and out phase (OP) images were generated. The STIR parameters were as follows: Coronal position scan, TR $=7599 \mathrm{~ms}$, TE $=70 \mathrm{~ms}$, TI $=230 \mathrm{~ms}$, FOV $=530 \mathrm{~mm} \times 251 \mathrm{~mm} \times 300 \mathrm{~mm}$, matrix $=528 \times 528$, slice thickness $=6 \mathrm{~mm}$, slice $\mathrm{gap}=1 \mathrm{~mm}$, slices $=36$, scanning segments $=6$, total scan time $=3$ min 2 s. After scanning, a dedicated workstation (Extended MR Workspace2.6.3.5, Philips Healthcare) was used to perform maximum intensity projection reconstructions for all raw axial DWIBS images, and the reconstructed images were visualized by using black-white inversion technology.

\section{Image processing and analysis}

Two radiologists (MTS and YZ) were responsible for analyzing the MRI images of all MM patients to determine the infiltration pattern and the number and sites of bone marrow-involved lesions. Both radiologists were blinded to the patients' clinical data, except for gender and age, before reviewing the images. MM infiltration patterns were classified into five categories according to MRI presentation (12): normal pattern, focal infiltration pattern (lesion diameter $\geq 5 \mathrm{~mm}$ ), diffuse infiltration pattern, combined focal and diffuse infiltration pattern, and salt-and-pepper. The diagnostic criteria for marrow infiltration by myeloma cells, either focal or diffuse were: (I) the signal intensity of the lesion in mDIXON IP was equal or lower than the signal intensity of non-degenerated intervertebral disc in mDIXON IP; (II) lesion signal intensity in the STIR sequence was higher than the signal intensity for muscles; (III) lesions showed high signals at $\mathrm{b}=0$ and $800 \mathrm{~s} / \mathrm{mm}^{2}$ DWI; and (IV) the FF of the lesion measured by mDIXON was lower than $20 \%$ (25). FLs with a diameter of at least $5 \mathrm{~mm}$ that met all the above criteria were considered to indicate focal infiltration by myeloma cells. A diffuse infiltration pattern in which a normal bone marrow signal intensity was completely absent also needed to meet all the above criteria. Patients with a combined focal and diffuse infiltration pattern were assigned to the group with the more dominant pattern in each respective case, and patients with a salt-and-pepper pattern were assigned to the diffuse pattern group (9).

A third radiologist (CPR) reviewed all results, and the consensus was reached through discussion when there were differences in opinion.

Two radiologists (YHL and YL) employed the Philips postprocessing workstation (Extended MR Workspace 2.6.3.5, Philips Healthcare) for reconstructing the ADC map. The original DWI, STIR, and mDIXON images were used as references to select the slice with the maximum lesion diameter, and the region of interest (ROI) was manually drawn to obtain the mean ADC value. Following this, the ROI was manually drawn on the $W$ image of mDIXON and replicated on the $\mathrm{F}$ image's corresponding slice. The average from three measurements was used, and the FF was calculated by using the formula:

$$
\mathrm{FF}=\left[\mathrm{SI}_{\mathrm{F}} /\left(\mathrm{SI}_{\mathrm{F}}+\mathrm{SI}_{\mathrm{W}}\right)\right] \times 100 \%
$$

The specific measurement criteria were as follows: (I) For patients with a diffuse infiltration pattern, the corresponding $\mathrm{ROI}$ in visible marrow areas within the vertebral bodies, pelvis, femora, proximal humeri, and sternum, and mean values of these regions were calculated. (II) For MM patients with a focal infiltration pattern, all the myelomatous infiltration lesions with no artifacts were selected, and the mean of these regions was calculated. (III) For MM patients with a normal pattern, the evaluation methods were the same as that of a diffuse infiltration pattern.

The ROI was selected while avoiding the cortical bone and any non-myelomatous infiltration lesions such as vertebral hemangioma, degenerative endplate inflammation, and enostosis.

\section{Statistical methods}

The normality of the data was tested using SAS statistical software (version 9.4, USA), where normally distributed data were expressed as mean \pm standard deviation. Parameters having a non-normal distribution were expressed as median (Q1, Q3), and an intra-group correlation coefficient (ICC) was applied to evaluate the consistency of ADC and FF measured by the two observers. If multiple sets of ADC, $\mathrm{FF}$, and the numbers of FLs were consistent with the homogeneity of variance, one-way ANOVA was used to compare different DS stages, ISS stages, and R-ISS stages, and when this did not occur, the Kruskal-Wallis test was used. When the inter-group difference was statistically 
Table 1 Relevant data of 95 patients with newly diagnosed MM

\begin{tabular}{|c|c|}
\hline Variables & Number/median (range)/mean $\pm \mathrm{SD}$ \\
\hline Sex (male/female) & $60 / 35$ \\
\hline Age (years) ${ }^{*}$ & 62 (44 to 84$)$ \\
\hline Chain isotype (lgG/lgA) & $46 / 17$ \\
\hline Light chain & 32 \\
\hline \multicolumn{2}{|l|}{ Laboratory findings } \\
\hline $\mathrm{HB}(\mathrm{g} / \mathrm{L})^{\#}$ & $95 \pm 27$ \\
\hline Calcium (mmol/L)* & $2.26(2.09,2.41)$ \\
\hline Albumin $(g / L)^{\#}$ & $32.8 \pm 7.4$ \\
\hline Creatinine $(\mu \mathrm{mol} / \mathrm{L})^{*}$ & $100(74,192)$ \\
\hline$\beta 2-M G(m g / L){ }^{*}$ & $5.55(3.34,11.31)$ \\
\hline $\mathrm{LDH}(\mathrm{U} / \mathrm{L})^{*}$ & $194(150,251)$ \\
\hline $\mathrm{CRP}(\mathrm{mg} / \mathrm{L})^{*}$ & $3.20(1.17,9.90)$ \\
\hline BMPCs $(\%)^{\#}$ & $33.6 \pm 23.1$ \\
\hline $\begin{array}{l}\text { Serum M-protein } \\
\text { monoclonal }(\mathrm{g} / \mathrm{L})^{\#}\end{array}$ & $45.2 \pm 30.1$ \\
\hline Free light chain $(\mathrm{mg} / \mathrm{L})^{\#}$ & $4,076.5 \pm 4,980.1$ \\
\hline $\begin{array}{l}\text { sFLC-ratio }(\%)(0.01- \\
100 />100 \text { or }<0.01)\end{array}$ & $58 / 37$ \\
\hline FCM (\%) & $6.5(1.9,21.4)$ \\
\hline DS stage (I/II/III) & $21 / 11 / 63$ \\
\hline ISS stage (I/II/III) & $10 / 36 / 49$ \\
\hline R-ISS stage (I/II/III) & $9 / 64 / 22$ \\
\hline
\end{tabular}

\#, expressed as mean \pm standard deviation; *, expressed as

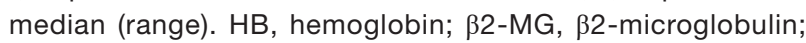
$\mathrm{LDH}$, lactic dehydrogenase; CRP, C-reactive protein; BMPCs, bone marrow plasma cells; Serum M-protein, serum monoclonal protein; sFLC-ratio, involved/uninvolved serum free light-chain ratio; FCM, flow cytometry of bone marrow cells; DS, DurieSalmon; ISS, International Staging System; R-ISS, Revised International Staging System.

significant, the Student-Newman-Keuls test or DwassSteel-Critchlow-Fligner test was used for intra-group multiple comparisons. The Spearman correlation test was used to correlate ADC, FF, and numbers of FLs against prognostic biomarkers of different MM infiltration patterns. Finally, two independent sample t-tests were performed to evaluate differences in ADC, FF, and numbers of FLs between different sFLC-ratio groups. All test statistics with $\mathrm{P}<0.05$ were considered statistically significant.

The dataset was available from figshare (https://doi. org/10.6084/m9.figshare.14204678.v2).

\section{Results}

\section{Patient characteristics}

A total of 95 newly diagnosed MM patients were included in this study, and their clinical characteristics are shown in Table 1. Among these, the MRI presentation was normal in 36 patients (Figure 1), had a diffuse pattern in 27 patients (Figure 2), and had a focal infiltration pattern in 32 patients (Figure 3). No combined focal and diffuse infiltration pattern or salt-and-pepper patients were included.

\section{Comparison of ADC and FF between different DS, ISS, and R-ISS stages}

As an indicator of inter-observer agreement, the ICC values of ADC and FF measured by the two radiologists were 0.828 (95\% CI, 0.752-0.882) and 0.890 (95\% CI, 0.839-0.925), which suggested that the observed measurements of ADC and $\mathrm{FF}$ were almost identical.

To evaluate ADC and FF in different DS, ISS, and R-ISS stages, we compared the values of ADC and FF, and the results demonstrated that the $\mathrm{ADC}$ and $\mathrm{FF}$ were significantly different among DS, ISS, and R-ISS stages in patients with a normal/diffuse infiltration pattern (Table 2). Specifically, after multiple comparisons within the subgroups of DS, ISS, and R-ISS stages, the ADC in stage I and II of DS, ISS, and R-ISS staging systems were lower than that in stage III, while the FF was conversely higher in stage I and II compared with that in stage III. However, there was no statistically significant difference between stage I and stage II (Figure 4).

In patients with a focal infiltration pattern, the ADC, FF, and numbers of FLs were not significantly different between various DS, ISS, and R-ISS stages, except for the numbers of FLs between stage II and III of the DS stages. Patients with DS stage III had markedly more FLs compared with DS stage II (Table 3).

\section{Correlation analysis of ADC and FF against prognostic biomarkers in different infiltration patterns}

We further detected the correlations between ADC, FF, and clinical prognostic biomarkers, including $\mathrm{HB}$, calcium, albumin, creatinine, $\beta 2-M G$, LDH, CRP, BMPCs, serum monoclonal protein, serum-free light chain, and FCM 


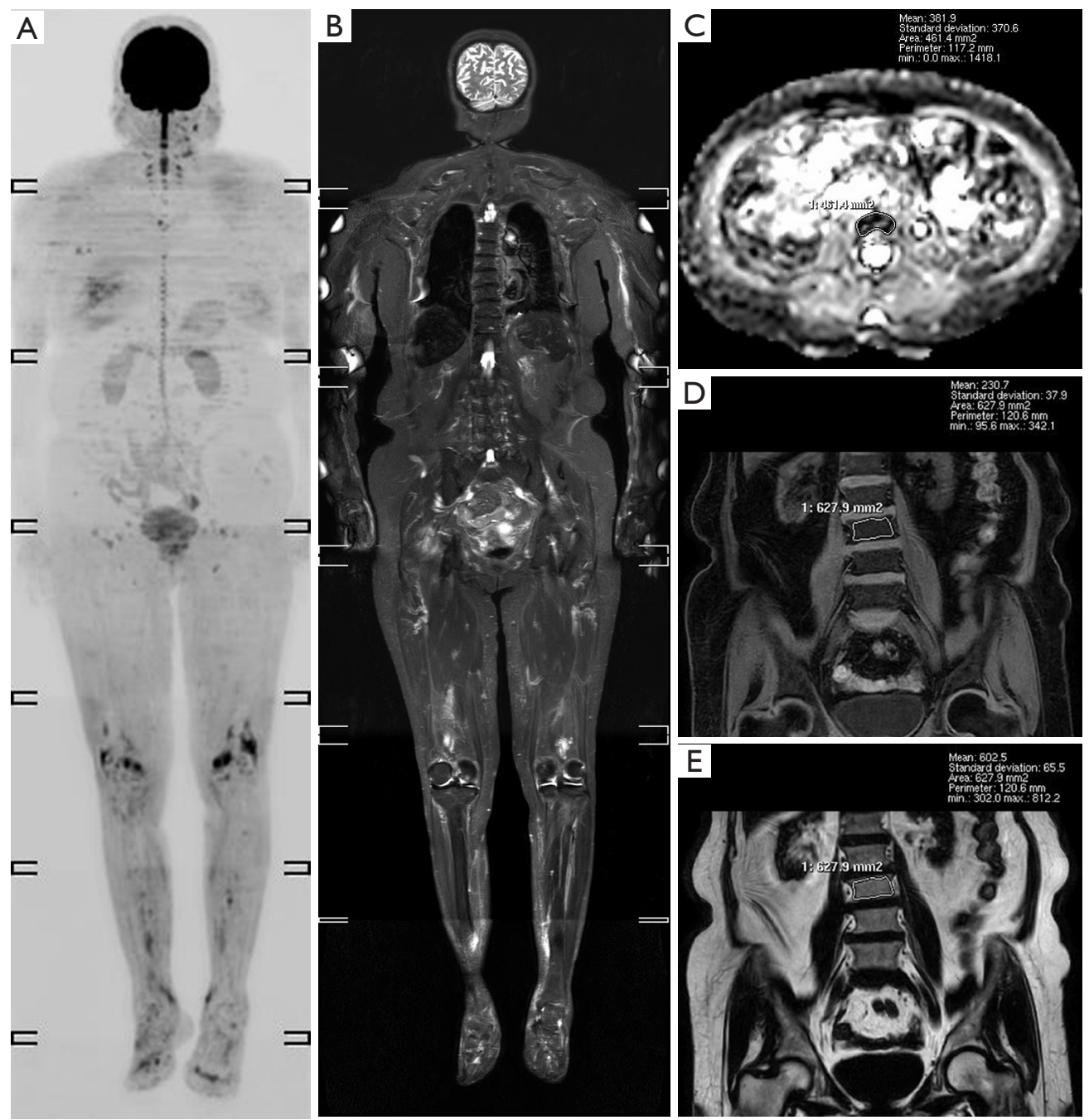

Figure 1 A 77-year-old female MM patient with a normal MRI presentation. (A) DWIBS and (B) short TI inversion recovery (STIR) shows no myelomatous infiltration lesions. (C) The apparent diffusion coefficient (ADC) map of the 3rd lumbar vertebral body shows that the mean ADC value is $0.38 \times 10^{-3} \mathrm{~mm}^{2} / \mathrm{s}$. According to the (D) W image and (E) F image in mDIXON, the mean fat fraction of the $3 \mathrm{rd}$ lumbar vertebral body is $72.3 \%$. STIR, short TI inversion recovery; DWIBS, diffusion-weighted whole-body imaging with background body signal suppression.

in different infiltration patterns. In the normal/diffuse infiltration pattern, the ADC was negatively correlated with $\mathrm{HB}$ and positively correlated with $\beta 2-\mathrm{MG}$, BMPCs, serum monoclonal protein, and FCM. Conversely, the FF was positively correlated with $\mathrm{HB}$ and negatively correlated with $\beta 2-M G, L D H, B M P C s$, serum monoclonal protein, and FCM (Table 4).

In patients with a focal infiltration pattern, we detected a negative correlation between ADC and $\beta 2-\mathrm{MG}, \mathrm{ADC}$, and CRP and a positive correlation between the numbers of FLs and creatinine, but not with other prognostic biomarkers.
Furthermore, there were no significant correlations between $\mathrm{FF}$ and clinical prognostic biomarkers in patients with a focal infiltration pattern (Table 5).

Lastly, we used sFLC-ratio ratios of 100 and 0.01 to divide patients into low $(0.01-100)$ and high $(>100$ or $<0.01)$ sFLC-ratio groups and compared ADC and FF between the two groups under different infiltration patterns. No significant differences of ADC between the low and high sFLC-ratio groups were observed in patients with a normal/ diffuse infiltration pattern $(\mathrm{P}=0.158)$, whereas $\mathrm{FF}$ was higher in the low sFLC-ratio group compared with the high sFLC- 

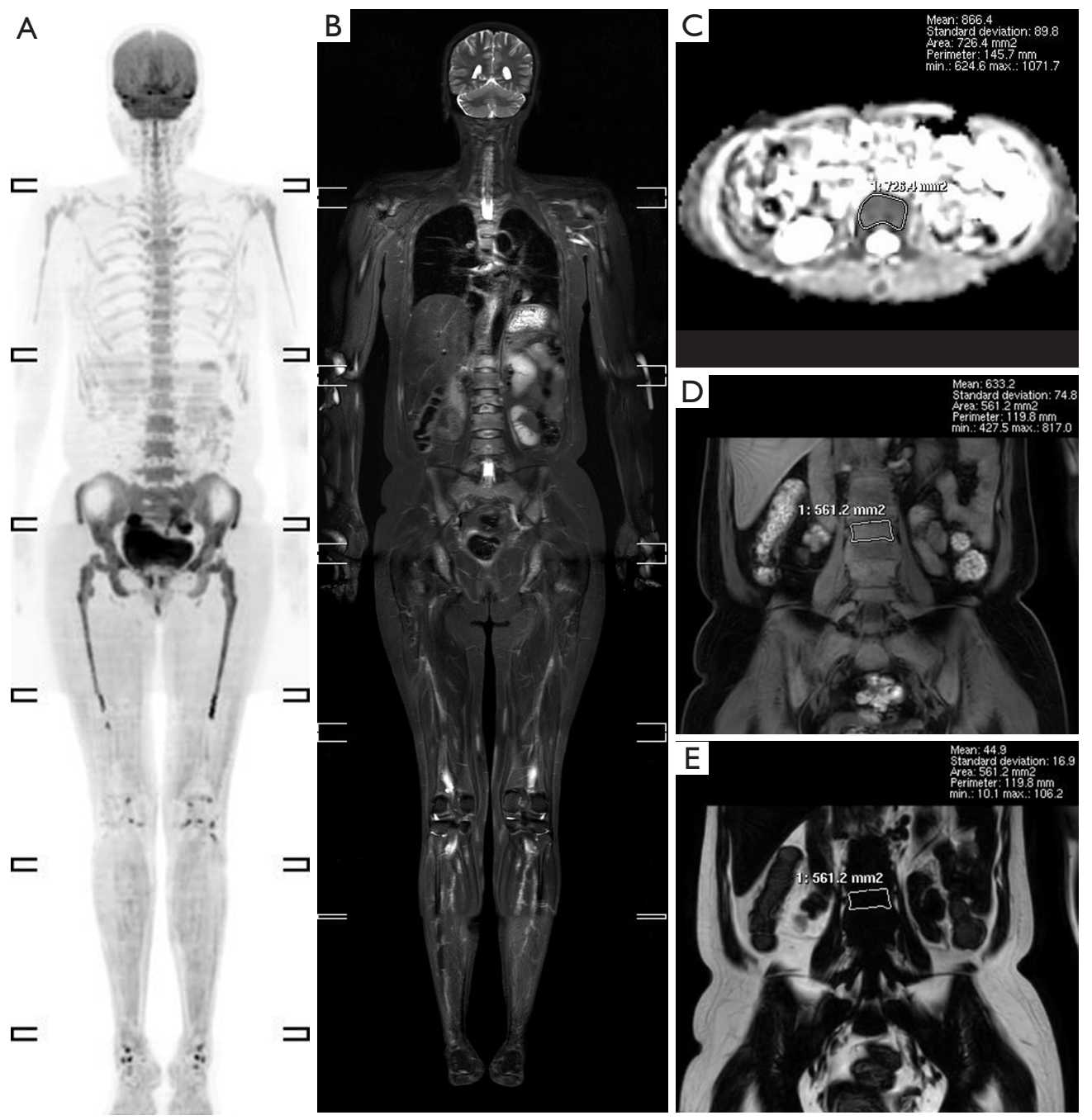

Figure 2 A 50-year-old female MM patient with a diffuse infiltration MRI presentation. (A) DWIBS and (B) STIR shows diffuse signal abnormalities in the axial skeleton, pelvis, bilateral humerus, and femur. (C) The ADC map of the 3rd lumbar vertebral body shows that the mean ADC value is $0.87 \times 10^{-3} \mathrm{~mm}^{2}$. According to the (D) $\mathrm{W}$ image and (E) F image in mDIXON, the mean fat fraction of the 3rd lumbar vertebral body is $6.6 \%$. STIR, short TI inversion recovery; DWIBS, diffusion-weighted whole-body imaging with background body signal suppression; ADC, apparent diffusion coefficient.

ratio group $(\mathrm{P}=0.023)$. There were no significant differences in $\mathrm{ADC}, \mathrm{FF}$, and numbers of FLs between the low and high sFLC-ratio groups within focal infiltration pattern patients, $\mathrm{P}=0.762, \mathrm{P}=0.918$ and $\mathrm{P}=0.774$, respectively (Table 6).

\section{Discussion}

Our study demonstrated that ADC and FF values from DWIBS and mDIXON functional MRI changed with DS, ISS, and R-ISS staging in patients with a normal/diffuse infiltration pattern, but not in the population with a focal infiltration pattern. Additionally, a significant correlation between $\mathrm{ADC} / \mathrm{FF}$ and clinical prognostic biomarkers was observed primarily in the normal/diffuse infiltration pattern group. After disease stratification by sFLC-ratio, a higher FF was observed in the low sFLC-ratio group compared with the high sFLC-ratio group.

MM is a highly heterogeneous hematological malignancy with varied survival outcomes. In recent years, various highrisk factors for $M M$ have been elucidated, and different staging systems have been established via combining sensitive biochemical and cytogenetic indicators with MM 


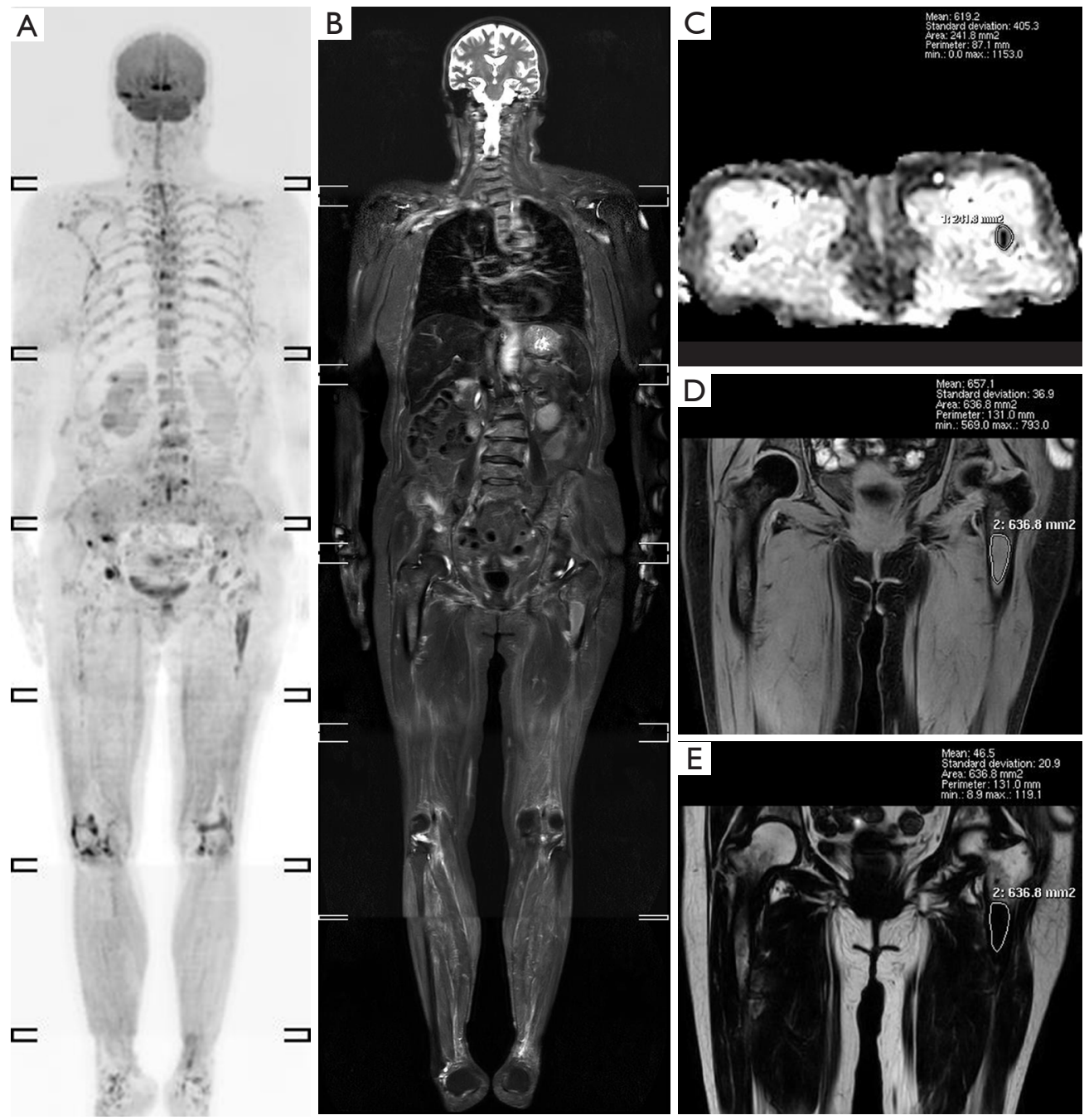

Figure 3 A 73-year-old female MM patient with a focal infiltration MRI presentation. (A) DWIBS and (B) STIR shows multiple focal signal abnormalities, of which the lesion with the largest diameter is located at the upper segment of the left femur. (C) The ADC map of the left femur's upper segment shows that the mean ADC value is $0.62 \times 10^{-3} \mathrm{~mm}^{2} / \mathrm{s}$. According to the (D) W image and (E) F image in mDIXON, the mean fat fraction of the upper segment of the left femur is $6.6 \%$. STIR, short TI inversion recovery; DWIBS, diffusion-weighted wholebody imaging with background body signal suppression; ADC, apparent diffusion coefficient.

diagnostic criteria. Functional MRI can provide additional information about the amount of infiltrating myeloma cells and the degree of bone marrow infiltration. It is crucial to integrate this method into the existing prognostic factors to establish a more comprehensive MM prognosis evaluation system. Our results showed that ADC and FF values significantly differed between different DS, ISS, and R-ISS stages and changed as the stage progressed in the normal/ diffuse infiltration pattern, but not in the focal infiltration pattern. Specifically, the ADC values increased as the stage progressed, while the $\mathrm{FF}$ values decreased as the stage progressed. This suggests that ADC and FF may serve as supplemental markers to the recent staging systems in $M M$ patients with a normal/diffuse infiltration pattern.

In contrast to a normal/diffuse infiltration pattern, we found no significant difference in ADC or FF between different DS, ISS, and R-ISS stages in patients with a focal infiltration pattern, except for a difference in the numbers of FLs between DS stage II and III. Previous work has shown that the genome map differs between FLs and the iliac crest, indicating that spatial clonal heterogeneity is present in FLs (6). Danner et al. analyzed 112 focal MM lesions from 39 patients using 
Table 2 Comparison of ADC and FF between different DS, ISS, and R-ISS stages in patients with a normal/diffuse infiltration pattern

\begin{tabular}{|c|c|c|c|c|c|c|}
\hline Stage & \multicolumn{2}{|c|}{ DS stage } & \multicolumn{2}{|c|}{ ISS stage } & \multicolumn{2}{|c|}{ R-ISS stage } \\
\hline I & $0.39 \pm 0.10^{*}$ & $52.4 \pm 15.7^{\star}$ & $0.44 \pm 0.14^{*}$ & $55.4 \pm 14.8^{*}$ & $0.44 \pm 0.14^{*}$ & $55.4 \pm 14.8^{\star}$ \\
\hline II & $0.46 \pm 0.10^{*}$ & $49.4 \pm 18.4^{*}$ & $0.48 \pm 0.19^{*}$ & $41.6 \pm 22.2^{*}$ & $0.53 \pm 0.21^{*}$ & $38.7 \pm 22.6^{\star}$ \\
\hline III & $0.66 \pm 0.22$ & $23.9 \pm 20.9$ & $0.64 \pm 0.21$ & $27.0 \pm 22.4$ & $0.69 \pm 0.22$ & $18.7 \pm 19.2$ \\
\hline $\mathrm{P}$ & $<0.001$ & $<0.001$ & 0.005 & 0.005 & 0.015 & 0.002 \\
\hline
\end{tabular}

*, significant change $(\mathrm{P}<0.05)$ compared with stage III. $\mathrm{H}$ is the statistic of the Kruskal-Wallis test, and $\mathrm{F}$ is the statistic of one-way ANOVA. ADC, apparent diffusion coefficient; FF, fat fraction; DS, Durie-Salmon; ISS, International Staging System; R-ISS, Revised International Staging System.

a T2-weighted Dixon sequence and found no significant correlation between FF and myeloma-defining events (26). This data suggests no significant correlation exists between $\mathrm{ADC}$ and FF measurements in FLs and bone marrow examination of the iliac crest.

To further examine the prognostic values of DWIBS and mDIXON in MM patients, we analyzed the correlation between $\mathrm{ADC} / \mathrm{FF}$ and clinical prognostic biomarkers. We determined that ADC was negatively correlated with $\mathrm{HB}$ and positively correlated with $\beta 2-M G$, BMPCs, serum monoclonal protein, and FCM in patients with a normal/diffuse infiltration pattern. However, FF results were opposite to ADC in patients with a normal/diffuse infiltration pattern. The bone marrow of MM patients with diffuse infiltration often presents with active hyperplasia, reduced yellow bone marrow, and increased abnormal plasma cells (25). These characteristics accelerate the diffusion of extracellular water molecules, increasing ADC values and decreasing FF (27). However, our data did not show a similar trend of increasing ADC and decreasing FF in a normal/diffuse infiltration pattern as compared to a focal infiltration pattern.

As previously shown, HB, $\beta 2-M G, L D H, B M P C s, ~ F C M$, and serum monoclonal protein are markers indicating MM tumor burden, tumor cell proliferation rate, and invasiveness. A few studies have shown that MM patients with a diffuse infiltration pattern generally have poor prognostic characteristics, including severe anemia, higher $\mathrm{LDH}$, higher $32-\mathrm{MG}$, and elevated BMPCs $(9,28-30)$. A previous study analyzed 228 symptomatic MM patients and showed that diffuse infiltration is associated with bone marrow angiogenesis and capillary density and reflects high disease activity (9). Kloth et al. conducted WB-MRI examinations in 547 newly diagnosed monoclonal plasma cell disease patients and classified diffuse infiltration into "salt-and-pepper", moderate, and severe patterns and found the serum M protein and BMPCs ratio differed significantly among these patterns (31). Evaluating our results in the context of this previous work, we conclude measurement of $\mathrm{ADC}$ and $\mathrm{FF}$ can provide quantitative markers of tumor burden and that these are important for assessing the biological behavior of MM.

We only detected a negative correlation between ADC and $\beta 2-M G, A D C$ and $C R P$, and a positive correlation between the numbers of FLs and creatinine in patients with a focal infiltration pattern. While a diffuse infiltration pattern is relatively homogenous and a quantitative measure can help estimate tumor burden from diffuse infiltration, this may not apply to FLs. The exact quantification requires measurement of the total tumor volume by segmenting all FLs present (7). In combination with the approach of segmenting all FLs, quantitative imaging could provide objective information about each FL, which may be used in subsequent Radiomics or AI analysis of the bone marrow.

In 2014, the International Myeloma Working Group included the sFLC-ratio in the diagnostic criteria for MM, and sFLC-ratio $>100$ is considered as a biomarker for ultrahigh-risk smoldering MM patients (32). Dispenzieri et al. included the sFLC-ratio in the smoldering MM risk model, and the 5-year progression rates for high-, medium-, and low-risk groups were $76 \%, 51 \%$, and $25 \%$, respectively. That group concluded that the sFLC-ratio could be an important prognostic factor for smoldering MM (31). Therefore, we used an sFLC-ratio threshold value of 100 to divide patients into low and high sFLC-ratio groups and compared their ADC and FF values. Our study, for the first time, detected a correlation between the sFLC-ratio and functional MRI parameters. We found no significant 

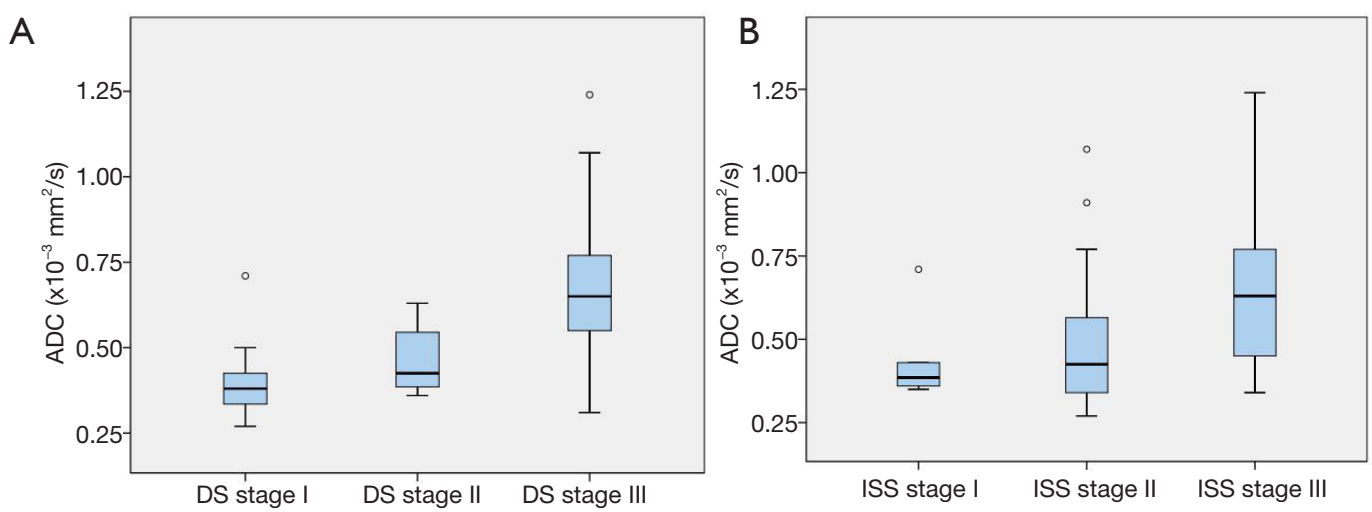

C

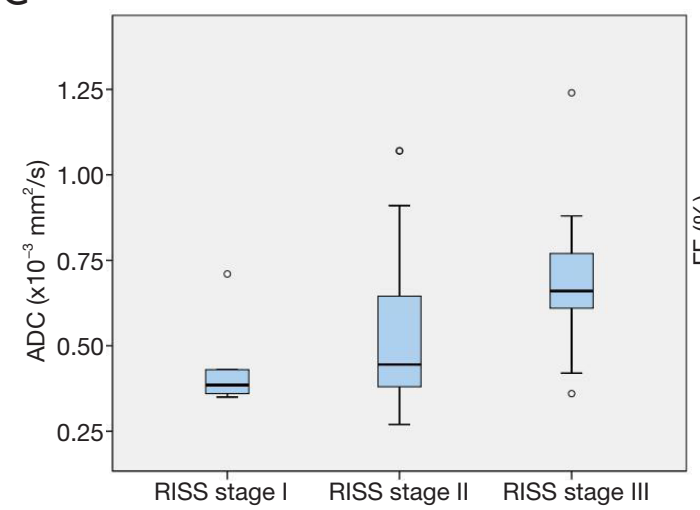

D

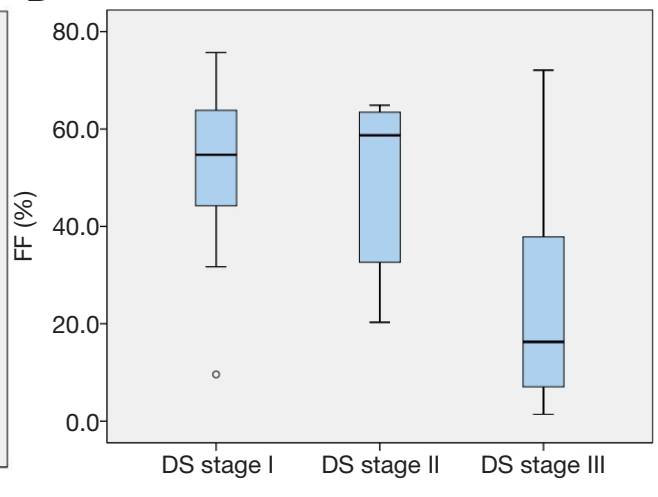

E
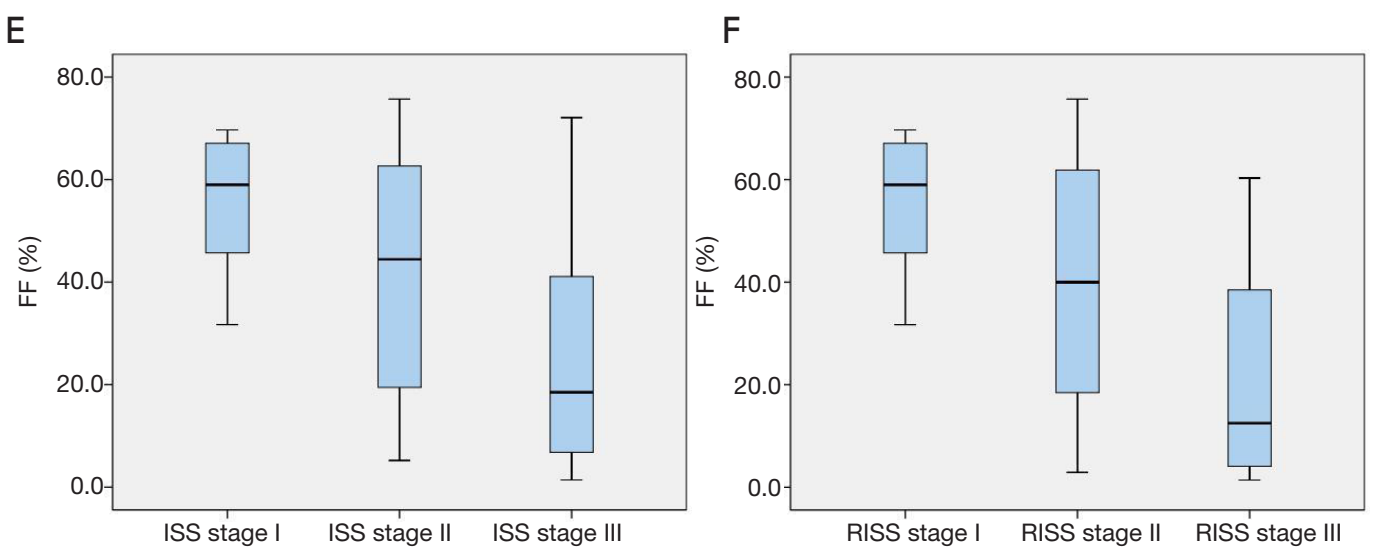

Figure 4 Box plots of apparent diffusion coefficient $(\mathrm{A}, \mathrm{B}, \mathrm{C})$ and fat fraction (D,E,F) of different DS, ISS, and R-ISS stages in MM patients with a normal/diffuse infiltration pattern.

differences in ADC between low and high sFLC-ratio groups in patients with a normal/diffuse infiltration pattern $(\mathrm{P}=0.158)$, whereas $\mathrm{FF}$ was higher in the low sFLC-ratio group compared with the high sFLC-ratio group $(\mathrm{P}=0.023)$. In patients with a focal infiltration pattern, $\mathrm{ADC}$ and $\mathrm{FF}$ did not significantly differ between low and high sFLCratio groups $(\mathrm{P}=0.762$ and $\mathrm{P}=0.918$, respectively). One possible reason for this finding is that more factors affect bone marrow $\mathrm{ADC}$ measurements than FF such as the bone marrow cell count, cell morphology, intracellular nuclearcytoplasmic ratio, and size of extracellular spaces, and cell membrane adhesion (33). A previous study reported that $\mathrm{FF}$ values are significantly decreased in the lumbar spine of MM patients when compared with healthy controls, 
Table 3 Comparison of ADC, FF, and numbers of focal lesions between different DS, ISS, and R-ISS stages in patients with a focal infiltration pattern

\begin{tabular}{|c|c|c|c|c|c|c|c|c|c|}
\hline Stage & \multicolumn{3}{|c|}{ DS stage } & \multicolumn{3}{|c|}{ ISS stage } & \multicolumn{3}{|c|}{ R-ISS stage } \\
\hline II & $0.87 \pm 0.05$ & $13.8 \pm 4.4$ & $2(2,2)^{\star}$ & $0.97 \pm 0.21$ & $14.4 \pm 5.4$ & $10.5 \pm 10.3$ & $0.91 \pm 0.17$ & $13.9 \pm 4.8$ & $14.6 \pm 12.9$ \\
\hline III & $0.86 \pm 0.20$ & $13.3 \pm 6.1$ & $19.6 \pm 13.8$ & $0.82 \pm 0.17$ & $13.0 \pm 6.7$ & $19.7 \pm 15.9$ & $0.78 \pm 0.22$ & $13.0 \pm 9.2$ & $21.6 \pm 18.1$ \\
\hline$P$ & 0.518 & 0.212 & 0.008 & 0.150 & 0.610 & 0.172 & 0.102 & 0.879 & 0.560 \\
\hline
\end{tabular}

*, significant change $(\mathrm{P}<0.05)$ compared with stage III. $\mathrm{F}$ is the statistic of one-way ANOVA, and $\mathrm{H}$ is the statistic of the Kruskal-Wallis test. ADC, apparent diffusion coefficient; FF, fat fraction; DS, Durie-Salmon; ISS, International Staging System; R-ISS, Revised International Staging System.

Table 4 Correlation analysis of ADC, and FF against prognostic biomarkers in patients with a normal/diffuse infiltration pattern.

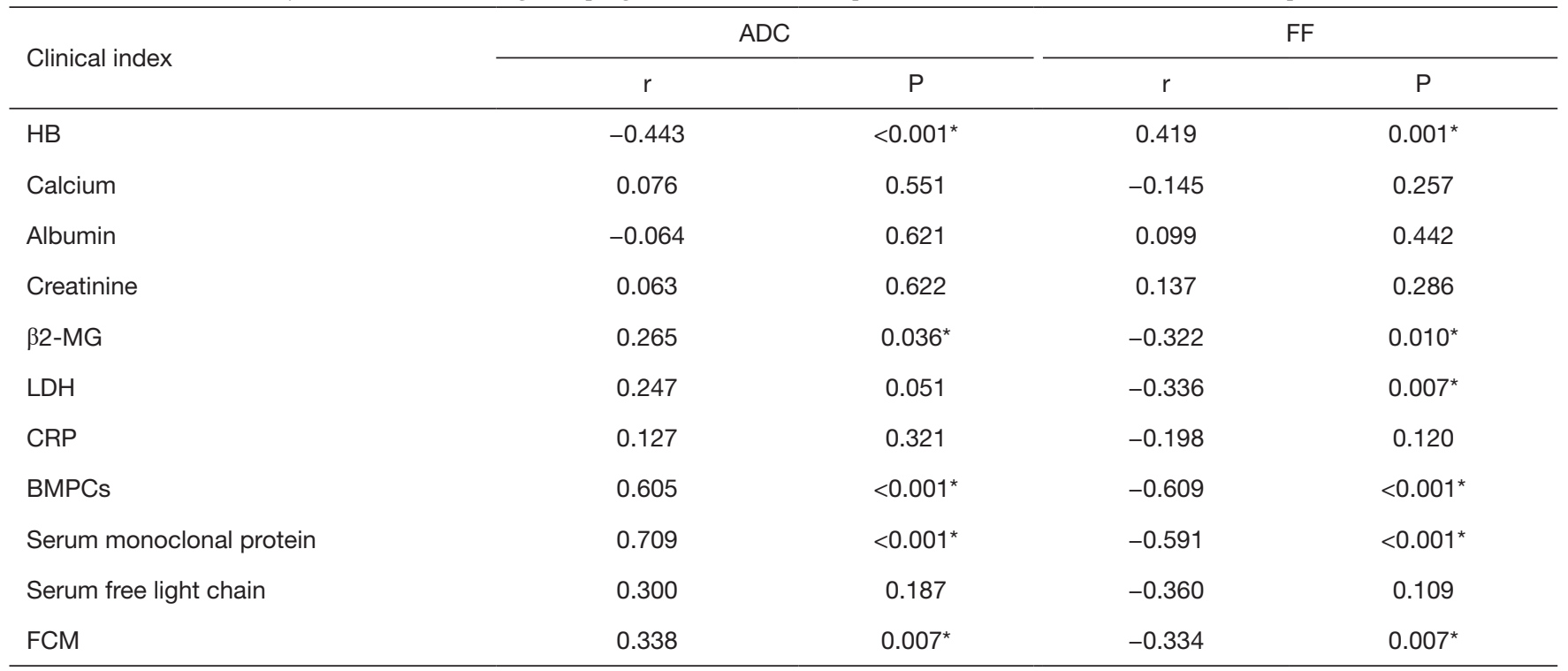

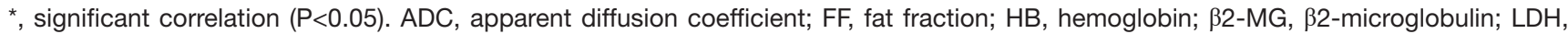
lactic dehydrogenase; $\mathrm{CRP}=\mathrm{C}$-reactive protein; BMPCs, bone marrow plasma cells; FCM, flow cytometry of bone marrow cells.

suggesting that $\mathrm{FF}$ is a favorable prognostic factor for MM (34). A higher sFLC-ratio has been associated with treatment non-response and disease progression in MM, making it an unfavorable prognostic factor for MM (35-37). Consistent with these data, we detected a negative correlation between FF values and the sFLC-ratio in patients with a normal/diffuse pattern. Therefore, we speculate that $\mathrm{FF}$ measurements can provide supplementary information to sFLC-ratio values and reflect proliferation levels in myeloma cells more accurately.
This study has some limitations. Firstly, the major limitation of the mDIXON method used in this study is its inherent inability to consider uncompensated $\mathrm{T}^{*}$ * effects. In the future, we plan to use mDIXON Quant instead of mDIXON, which will deliver more accurate and reproducible fat quantification. Secondly, pathological tests were not carried out to confirm focal infiltration lesions for the sample collection, and a definitive diagnosis of all lesions as this was not ethically permissible. We combined the established patterns reported in previous literature 
Table 5 Correlation analysis of ADC, FF, and numbers of focal lesions against prognostic biomarkers in patients with a focal infiltration pattern.

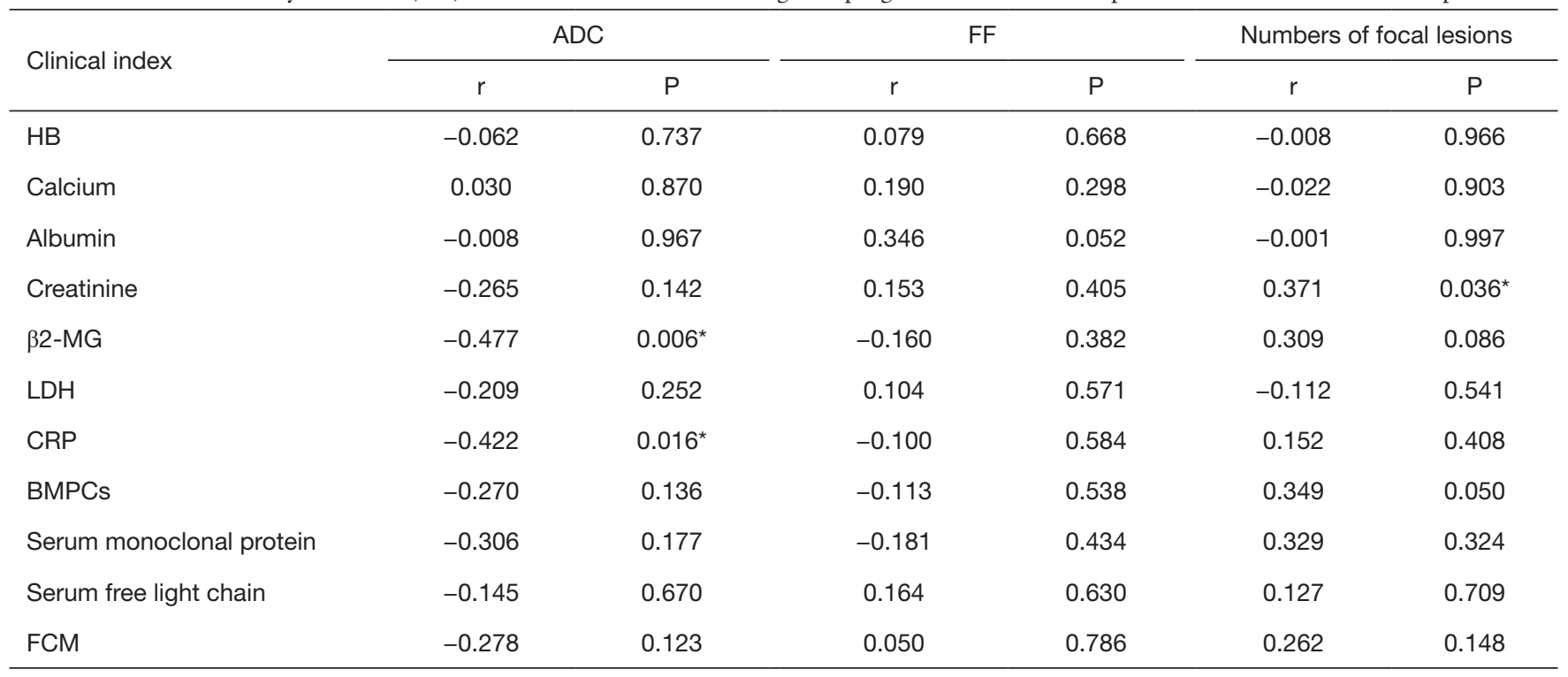

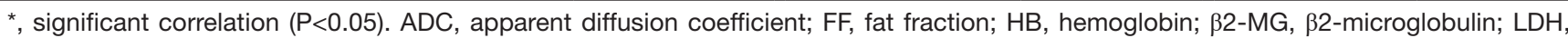
lactic dehydrogenase; $\mathrm{CRP}=\mathrm{C}$-reactive protein; BMPCs, bone marrow plasma cells; FCM, flow cytometry of bone marrow cells.

Table 6 Comparison of ADC, FF, and numbers of focal lesions between low and high sFLC-ratio groups in patients with different infiltration patterns

\begin{tabular}{|c|c|c|c|c|c|}
\hline sFLC-ratio & \multicolumn{2}{|c|}{ Normal/diffuse infiltration pattern } & \multicolumn{3}{|c|}{ Focal infiltration pattern } \\
\hline Low ratio group & $0.52 \pm 0.24$ & $41.2 \pm 22.7^{*}$ & $0.85 \pm 0.13$ & $13.8 \pm 6.6$ & $18.1 \pm 13.5$ \\
\hline High ratio group & $0.60 \pm 0.17$ & $27.4 \pm 22.4$ & $0.87 \pm 0.25$ & $13.6 \pm 5.6$ & $16.6 \pm 15.5$ \\
\hline $\mathrm{t}$ & -1.428 & 2.326 & -0.307 & 0.104 & 0.289 \\
\hline
\end{tabular}

*, significant change $(\mathrm{P}<0.05)$ compared with high ratio group. sFLC-ratio, involved/uninvolved serum free light-chain ratio; $A D C$, apparent diffusion coefficient; FF, fat fraction.

to confirm the focal infiltration lesions to address this issue. Thirdly, the sample size is small after stratification by different infiltration patterns resulting in fewer focal infiltration patients with DS and R-ISS stage I, which may bias the results.

Our study is the first to compare DWIBS-based ADC and mDIXON-based FF between different MM patients' stages and between different MRI morphological infiltration patterns (diffuse and focal). The results suggest that quantitative whole-body MR imaging can provide markers of MM patients' tumor burden with a normal/ diffuse infiltration pattern.

\section{Acknowledgments}

Funding: This work was supported by the He'nan Province Medical Science and Technique Foundation, China (No. LHGJ20190160).

\section{Footnote}

Conflicts of Interest: All authors have completed the ICMJE uniform disclosure form (available at http://dx.doi. org/10.21037/qims-20-1361). The authors have no conflicts of interest to declare. 
Ethical Statement: The authors are accountable for all aspects of the work in ensuring that questions related to the accuracy or integrity of any part of the work are appropriately investigated and resolved. The study was conducted in accordance with the Declaration of Helsinki (as revised in 2013). This retrospective study was approved by the ethics committee of our hospital (ethics review No. 2020-ky-128), and individual consent for this retrospective analysis was waived.

Open Access Statement: This is an Open Access article distributed in accordance with the Creative Commons Attribution-NonCommercial-NoDerivs 4.0 International License (CC BY-NC-ND 4.0), which permits the noncommercial replication and distribution of the article with the strict proviso that no changes or edits are made and the original work is properly cited (including links to both the formal publication through the relevant DOI and the license). See: https://creativecommons.org/licenses/by-nc-nd/4.0/.

\section{References}

1. Kumar S, Paiva B, Anderson KC, Durie B, Landgren O, Moreau P, Munshi N, Lonial S, Bladé J, Mateos MV, Dimopoulos M, Kastritis E, Boccadoro M, Orlowski R, Goldschmidt H, Spencer A, Hou J, Chng WJ, Usmani SZ, Zamagni E, Shimizu K, Jagannath S, Johnsen HE, Terpos E, Reiman A, Kyle RA, Sonneveld P, Richardson PG, McCarthy P, Ludwig H, Chen W, Cavo M, Harousseau JL, Lentzsch S, Hillengass J, Palumbo A, Orfao A, Rajkumar SV, Miguel JS, Avet-Loiseau H. International Myeloma Working Group consensus criteria for response and minimal residual disease assessment in multiple myeloma. Lancet Oncol 2016;17:e328-46.

2. Sonneveld P, Avet-Loiseau H, Lonial S, Usmani S, Siegel D, Anderson KC, Chng WJ, Moreau P, Attal M, Kyle RA, Caers J, Hillengass J, San Miguel J, van de Donk NW, Einsele H, Blade J, Durie BG, Goldschmidt H, Mateos MV, Palumbo A, Orlowski R. Treatment of multiple myeloma with high-risk cytogenetics: a consensus of the International Myeloma Working Group. Blood 2016;127:2955-62.

3. Hillengass J, Fechtner K, Weber MA, Bäuerle T, Ayyaz S, Heiss C, Hielscher T, Moehler TM, Egerer G, Neben K, Ho AD, Kauczor HU, Delorme S, Goldschmidt H. Prognostic significance of focal lesions in whole-body magnetic resonance imaging in patients with asymptomatic multiple myeloma. J Clin Oncol 2010;28:1606-10.
4. Kastritis E, Moulopoulos LA, Terpos E, Koutoulidis $\mathrm{V}$, Dimopoulos MA. The prognostic importance of the presence of more than one focal lesion in spine MRI of patients with asymptomatic (smoldering) multiple myeloma. Leukemia 2014;28:2402-3.

5. Walker R, Barlogie B, Haessler J, Tricot G, Anaissie E, Shaughnessy JD Jr, Epstein J, van Hemert R, Erdem E, Hoering A, Crowley J, Ferris E, Hollmig K, van Rhee F, Zangari M, Pineda-Roman M, Mohiuddin A, Yaccoby S, Sawyer J, Angtuaco EJ. Magnetic resonance imaging in multiple myeloma: diagnostic and clinical implications. J Clin Oncol 2007;25:1121-8.

6. Rasche L, Angtuaco EJ, Alpe TL, Gershner GH, McDonald JE, Samant RS, Kumar M, Van Hemert R, Epstein J, Deshpande S, Tytarenko R, Yaccoby S, Hillengass J, Thanendrarajan S, Schinke C, van Rhee F, Zangari M, Walker BA, Barlogie B, Morgan GJ, Davies FE, Weinhold N. The presence of large focal lesions is a strong independent prognostic factor in multiple myeloma. Blood 2018;132:59-66.

7. Wennmann M, Kintzelé L, Piraud M, Menze BH, Hielscher T, Hofmanninger J, Wagner B, Kauczor HU, Merz M, Hillengass J, Langs G, Weber MA. Volumetry based biomarker speed of growth: Quantifying the change of total tumor volume in whole-body magnetic resonance imaging over time improves risk stratification of smoldering multiple myeloma patients. Oncotarget 2018;9:25254-64.

8. Baur-Melnyk A, Buhmann S, Dürr HR, Reiser M. Role of MRI for the diagnosis and prognosis of multiple myeloma. Eur J Radiol 2005;5 5:56-63.

9. Moulopoulos LA, Dimopoulos MA, Kastritis E, Christoulas D, Gkotzamanidou M, Roussou M, Koureas A, Migkou M, Gavriatopoulou M, Eleutherakis-Papaiakovou E, Gika D, Koutoulidis V, Terpos E. Diffuse pattern of bone marrow involvement on magnetic resonance imaging is associated with high risk cytogenetics and poor outcome in newly diagnosed, symptomatic patients with multiple myeloma: a single center experience on 228 patients. Am J Hematol 2012;87:861-4.

10. Mai EK, Hielscher T, Kloth JK, Merz M, Shah S, Raab MS, Hillengass M, Wagner B, Jauch A, Hose D, Weber MA, Delorme S, Goldschmidt H, Hillengass J. A magnetic resonance imaging-based prognostic scoring system to predict outcome in transplant-eligible patients with multiple myeloma. Haematologica 2015;100:818-25.

11. Wennmann M, Hielscher T, Kintzelé L, Menze BH, Langs G, Merz M, Sauer S, Kauczor HU, Schlemmer 
HP, Delorme S, Goldschmidt H, Weinhold N, Hillengass J, Weber MA. Spatial Distribution of Focal Lesions in Whole-Body MRI and Influence of MRI Protocol on Staging in Patients with Smoldering Multiple Myeloma According to the New SLiM-CRAB-Criteria. Cancers (Basel) 2020;12:2537.

12. Dimopoulos MA, Hillengass J, Usmani S, Zamagni E, Lentzsch S, Davies FE, Raje N, Sezer O, Zweegman S, Shah J, Badros A, Shimizu K, Moreau P, Chim CS, Lahuerta JJ, Hou J, Jurczyszyn A, Goldschmidt H, Sonneveld P, Palumbo A, Ludwig H, Cavo M, Barlogie B, Anderson K, Roodman GD, Rajkumar SV, Durie $\mathrm{BG}$, Terpos E. Role of magnetic resonance imaging in the management of patients with multiple myeloma: a consensus statement. J Clin Oncol 2015;33:657-64.

13. Koutoulidis V, Papanikolaou N, Moulopoulos LA. Functional and molecular MRI of the bone marrow in multiple myeloma. Br J Radiol 2018;91:20170389.

14. Sun M, Cheng J, Zhang Y, Bai J, Wang F, Meng Y, Li Z. Application of DWIBS in malignant lymphoma: correlation between ADC values and Ki-67 index. Eur Radiol 2018;28:1701-8.

15. Baxter GC, Graves MJ, Gilbert FJ, Patterson AJ. A Metaanalysis of the Diagnostic Performance of Diffusion MRI for Breast Lesion Characterization. Radiology 2019;291:632-41.

16. Bray TJ, Chouhan MD, Punwani S, Bainbridge A, Hall-Craggs MA. Fat fraction mapping using magnetic resonance imaging: insight into pathophysiology. $\mathrm{Br} \mathrm{J}$ Radiol 2018;91:20170344.

17. Aparisi Gómez MP, Ayuso Benavent C, Simoni P, Aparisi F, Guglielmi G, Bazzocchi A. Fat and bone: the multiperspective analysis of a close relationship. Quant Imaging Med Surg 2020;10:1614-35.

18. Schmeel FC, Luetkens JA, Enkirch SJ, Feisst A, Endler CH, Schmeel LC, Wagenhauser PJ, Traber F, Schild $\mathrm{HH}$, Kukuk GM. Proton density fat fraction (PDFF) MR imaging for differentiation of acute benign and neoplastic compression fractures of the spine. Eur Radiol 2018;28:5001-9.

19. Bray TJP, Singh S, Latifoltojar A, Rajesparan K, Rahman F, Narayanan P, Naaseri S, Lopes A, Bainbridge A, Punwani S, Hall-Craggs MA. Diagnostic utility of whole body Dixon MRI in multiple myeloma: A multi-reader study. PLoS One 2017;12:e0180562.

20. Anderson KC, Alsina M, Atanackovic D, Biermann JS, Chandler JC, Costello C, Djulbegovic B, Fung HC, Gasparetto C, Godby K, Hofmeister C, Holmberg L,
Holstein S, Huff CA, Kassim A, Krishnan AY, Kumar SK, Liedtke M, Lunning M, Raje N, Reu FJ, Singhal S, Somlo G, Stockerl-Goldstein K, Treon SP, Weber D, Yahalom J, Shead DA, Kumar R. NCCN Guidelines Insights: Multiple Myeloma, Version 3.2016. J Natl Compr Canc Netw 2016;14:389-400.

21. Caers J, Garderet L, Kortum KM, O’Dwyer ME, van de Donk N, Binder M, Dold SM, Gay F, Corre J, Beguin Y, Ludwig H, Larocca A, Driessen C, Dimopoulos MA, Boccadoro M, Gramatzki M, Zweegman S, Einsele H, Cavo M, Goldschmidt H, Sonneveld P, Delforge M, Auner HW, Terpos E, Engelhardt M. European Myeloma Network recommendations on tools for the diagnosis and monitoring of multiple myeloma: what to use and when. Haematologica 2018;103:1772-84.

22. Durie BG, Salmon SE. A clinical staging system for multiple myeloma. Correlation of measured myeloma cell mass with presenting clinical features, response to treatment, and survival. Cancer 1975;36:842-54.

23. Greipp PR, San Miguel J, Durie BG, Crowley JJ, Barlogie B, Blade J, Boccadoro M, Child JA, Avet-Loiseau H, Kyle RA, Lahuerta JJ, Ludwig H, Morgan G, Powles R, Shimizu K, Shustik C, Sonneveld P, Tosi P, Turesson I, Westin J. International staging system for multiple myeloma. J Clin Oncol 2005;23:3412-20.

24. Palumbo A, Avet-Loiseau H, Oliva S, Lokhorst HM, Goldschmidt H, Rosinol L, Richardson P, Caltagirone S, Lahuerta JJ, Facon T, Bringhen S, Gay F, Attal M, Passera R, Spencer A, Offidani M, Kumar S, Musto P, Lonial S, Petrucci MT, Orlowski RZ, Zamagni E, Morgan G, Dimopoulos MA, Durie BG, Anderson KC, Sonneveld P, San Miguel J, Cavo M, Rajkumar SV, Moreau P. Revised International Staging System for Multiple Myeloma: A Report From International Myeloma Working Group. J Clin Oncol 2015;33:2863-9.

25. Koutoulidis V, Fontara S, Terpos E, Zagouri F, Matsaridis D, Christoulas D, Panourgias E, Kastritis E, Dimopoulos MA, Moulopoulos LA. Quantitative Diffusion-weighted Imaging of the Bone Marrow: An Adjunct Tool for the Diagnosis of a Diffuse MR Imaging Pattern in Patients with Multiple Myeloma. Radiology 2017;282:484-93.

26. Danner A, Brumpt E, Alilet M, Tio G, Omoumi P, Aubry S. Improved contrast for myeloma focal lesions with T2weighted Dixon images compared to T1-weighted images. Diagn Interv Imaging 2019;100:513-9.

27. Padhani AR, Koh DM, Collins DJ. Whole-body diffusionweighted MR imaging in cancer: current status and research directions. Radiology 2011;261:700-18. 
28. Baur A, Bartl R, Pellengahr C, Baltin V, Reiser M. Neovascularization of bone marrow in patients with diffuse multiple myeloma: a correlative study of magnetic resonance imaging and histopathologic findings. Cancer 2004;101:2599-604.

29. Song MK, Chung JS, Lee JJ, Min CK, Ahn JS, Lee SM, Shin DY, Bae SH, Hong J, Lee GW, Lee IS, Shin HJ. Magnetic resonance imaging pattern of bone marrow involvement as a new predictive parameter of disease progression in newly diagnosed patients with multiple myeloma eligible for autologous stem cell transplantation. Br J Haematol 2014;165:777-85.

30. D'Anastasi M, Notohamiprodjo M, Schmidt GP, Dürr HR, Reiser MF, Baur-Melnyk A. Tumor load in patients with multiple myeloma: $\beta 2$-microglobulin levels versus whole-body MRI. AJR Am J Roentgenol 2014;203:854-62.

31. Kloth JK, Hillengass J, Listl K, Kilk K, Hielscher T, Landgren O, Delorme S, Goldschmidt H, Kauczor HU, Weber MA. Appearance of monoclonal plasma cell diseases in whole-body magnetic resonance imaging and correlation with parameters of disease activity. Int $\mathrm{J}$ Cancer 2014;135:2380-6.

32. Rajkumar SV, Dimopoulos MA, Palumbo A, Blade J, Merlini G, Mateos MV, Kumar S, Hillengass J, Kastritis E, Richardson P, Landgren O, Paiva B, Dispenzieri A, Weiss B, LeLeu X, Zweegman S, Lonial S, Rosinol L, Zamagni E, Jagannath S, Sezer O, Kristinsson SY, Caers J, Usmani SZ, Lahuerta JJ, Johnsen HE, Beksac M, Cavo M, Goldschmidt H, Terpos E, Kyle RA, Anderson KC, Durie BG, Miguel JF. International Myeloma Working Group

Cite this article as: Sun M, Cheng J, Ren C, Zhang Y, Li Y, Li Y, Zhang S. Quantitative whole-body MR imaging for assessment of tumor burden in patients with multiple myeloma: correlation with prognostic biomarkers. Quant Imaging Med Surg 2021;11(8):3767-3780. doi:10.21037/qims-20-1361 updated criteria for the diagnosis of multiple myeloma. Lancet Oncol 2014;15:e538-48.

33. Latifoltojar A, Hall-Craggs $M$, Rabin N, Popat R, Bainbridge A, Dikaios N, Sokolska M, Rismani A, D'Sa S, Punwani S, Yong K. Whole body magnetic resonance imaging in newly diagnosed multiple myeloma: early changes in lesional signal fat fraction predict disease response. Br J Haematol 2017;176:222-33.

34. Takasu M, Tani C, Sakoda Y, Ishikawa M, Tanitame K, Date S, Akiyama Y, Sakai A, Asaoku H, Kajima T, Awai K. Iterative decomposition of water and fat with echo asymmetry and least-squares estimation (IDEAL) imaging of multiple myeloma: initial clinical efficiency results. Eur Radiol 2012;22:1114-21.

35. Dispenzieri A, Kyle RA, Katzmann JA, Therneau TM, Larson D, Benson J, Clark RJ, Melton LJ, 3rd, Gertz MA, Kumar SK, Fonseca R, Jelinek DF, Rajkumar SV. Immunoglobulin free light chain ratio is an independent risk factor for progression of smoldering (asymptomatic) multiple myeloma. Blood 2008;111:785-9.

36. Barley K, Tindle S, Bagiella E, Jagannath S, Chari A. Serum Free Light Chain Assessment Early After Stem Cell Transplantation as a Prognostic Factor in Multiple Myeloma. Clin Lymphoma Myeloma Leuk 2015;15:541-5.

37. Özkurt ZN, Sucak GT, Akı ŞZ, Yağcı M, Haznedar R. Early Prognostic Value of Monitoring Serum Free Light Chain in Patients with Multiple Myeloma Undergoing Autologous Stem Cell Transplantation. Cancer Invest 2017;35:195-201. 